\title{
Software Error Indication using Artificial Neural Network and Strong Back Propagation
}

\author{
N. Priya, P. Nandhini, D.Jeya Priya, Nikita sharma
}

\begin{abstract}
Software designing field contains different methodologies identified with expectation, for example, test exertion forecast, redress cost expectation, blame expectation and so on. Among these product blame expectation is the most mainstream look into zone and numerous new tasks are begun around there. At the point when there is a mistake in the PC program, it delivers an invalid or false outcome. Henceforth expectation of inadequate modules is important to improve the product quality. Different techniques and metric sets are accessible to discover the false modules that are blunder inclined. In this, Artificial Neural Network based programming flaw forecast method is utilized. To discover assessed answers for improvement and inquiry issues this technique is utilized. Manufactured Neural Network is utilized for finding the flawed components and additionally to predict the mistaken modules.
\end{abstract}

Index Terms: ANN.Network, modelling

\section{INTRODUCTION}

Software deficiency forecast techniques utilize past programming parameters and blame information to anticipate the blamed modules for the following arrival of programming. For accomplishing the objective of a product quality confirmation activity, programming quality models are one of the helpful devices. This model can be utilized to perceive program modules that are imperfect. Programming issue is a blunder in the coding that may prompt programming to act not in the right way and this may bring about mistake and thus programming disappointment. Programming flaw which has happened because of programming mistake can be a recoverable blunder. [1-5] Once such blames are recognized they are sent to proper handler for performing required advances. Blame forecast will give a chance to the group to retest again the modules or records which are broken or for which the likelihood of fault is more. Investing more energy in the inadequate modules rather than non-faulty ones outcomes into appropriate asset use and this prompts support of the venture in less demanding way that is gainful for the two clients and undertaking proprietors.

Revised Manuscript Received on July 22, 2019.

N.Priya, Department of CSE, Bharath Institute of Higher Education and Research, Chennai, Tamilnadu, India.

P. Nandhini Department of CSE, Bharath Institute of Higher Education and Research, Chennai, Tamilnadu, India

D.Jeypriya, Department of CSE, Bharath Institute of Higher Education and Research, Chennai, Tamilnadu, India

Nikita Sharma, , Student,Department of CSE, Bharath Institute of Higher Education and Research, Chennai, Tamilnadu, India
The correct expectation of where the mistakes are likely to happen in code can enable specifically to test exertion, to improve the product quality and lessen costs. A blame vulnerable module is the one in which the amount of issues is higher than chosen limit. Today the best test in the product business is to make any application or programming totally blame allowed to accomplish the best programming. As the surrendered modules are remembered, it is less demanding for the specialists to concentrate just on the advancement work. Flawed modules can be effectively anticipated by characterizing programming modules into gatherings of defective and non-broken modules toward the start of advancement. [6-10]A few calculations have been utilized to foresee. the product blames, for example, k-implies bunching and progressive calculations. Bayes Network Classification Algorithm and spam separating techniques are likewise utilized for finding defective modules. Bolster vector machine (SVM) and module reliance diagrams (MDGs) are likewise useful in anticipating the shortcomings. Among different calculations Genetic Algorithms are valuable for settling grouping and also relapse issues. Along these lines for foreseeing the quality it is imperative to test the capacity of this calculation.

The paper is sorted out as takes after: area 2 examines the related work, Section 3 clarifies about the observational information accumulation and segment 4 depicts the GA based procedure. The aftereffect of the investigation is given in area 5. At long last finishes of the exploration are exhibited in area 6.

\section{RELATED WORK}

An audit was completed on programming designing for the most part on programming shortcoming expectation. In this examination almost around 90 papers were explored identified with blame forecast between the years 1990 and 2009. Both measurable based strategies and machine learning based techniques are considered in this paper. Subsequent to doing the study it is discovered that the majority of the models depended on machine learning procedures. This will profit scientists to get the information about the blame expectation. A multi-layer nourish forward counterfeit neural system (ANN)[11-15] based strategic development bend show (LGCM) is proposed in this paper for programming unwavering quality and forecast. A simulated neural system is being produced by portrayal of various elements of shrouded layer neurons. A neuro-hereditary is proposed for the ANN based LGCM by diminishing the weights of the system. In this the correlation of two learning calculations is additionally introduced to foresee the product dependability (Pratik Roy et al. 
2015). Examination was completed for outlining objective arranged quality model with legitimate asset usage utilizing hereditary based multi-target strategy. It exhibits a contextual investigation which demonstrates what modules are blame inclined or not. Favorable position[16-20] of utilizing hereditary writing computer programs is that it doesn't require extra data with respect to size and structure of the issu. The primary objective of this paper was to discover and assess the investigations with respect to the measurements utilized as a part of blame forecast. An outrageous pursuit was likewise done on computerized libraries. From each examination ten properties were drawn out and an appraisal was done to get new bits of knowledge. With the assistance of these investigations specialists can discover every now and again utilized measurements. Research was done on information mining systems that are utilized for looking through the guidelines that demonstrate the modules that has the shot of being imperfect. Datasets are utilized from storehouse. To start with highlight choice is connected on flawed properties and after that hereditary calculation is utilized. Like this blemished programming modules are discovered utilizing information mining.

This paper centersaround programming quality displaying by utilizing different information storehouses. It utilizes hereditary programming based approach for developing ideal models with the assistance of datasets. Benchmark Classifier, Validation Classifier, and Validation-and-Voting Classifier are the three procedures introduced in this paper. The outcomes demonstrate that last strategy is vastly improved than the others and has the less likelihood for over fitting (Liu, Yi Cathy et al. 2010). Disgraceful information is an imperative factor while building expectation models for high solid frameworks. With skewed information this paper utilizes Roughly Balanced Bagging calculation for blame expectation. For taking care of the issue it at that point blends information inspecting and sacking. At that point an examination is finished with the models without stowing. The adequacy of Quad Tree based K-Means bunching calculation is contrasted and unique[21-25] K - implies calculation in anticipating broken modules. The objective of this paper is twofold. In the first place, Quad trees are connected to discover group focuses that are given as contribution to K-implies calculation. At that point for recognizing issues calculation is utilized. This paper presented another hereditary programming calculation with regards to dependability demonstrating. In the wake of assessing this new one the outcomes demonstrate that it is less exorbitant when contrasted with traditional GP (Eduardo Oliveira Costa et al. 2010). Here consistency of unwavering quality is estimated by utilizing gathering of models prepared by GA. This examination is connected to three sets and results demonstrate that models are straight in future.

In this, close around 15 Bayesian system students are thought about. Among every one of the outcomes demonstrates that Augmented Naive Bayes classifiers gets better execution when contrasted with others. In a product organization to limit costs, blame and exertion forecast are principle errands. However prescient execution is relinquished. In this paper to settle this issue manage extraction is utilized. A half breed IEDA-SVR is proposed in this paper. It is utilized to anticipate the product unwavering quality. Here two informational collections are utilized and an examination with past models is done (Cong J et al. 2014). Here a strategy is suggested that goes for keeping away from the model-speculation issue. [26-30]The arrangement is to reuse the current the models to produce new ones having both general and particular learning. This paper tackles the issue of anticipating exertion that is expected to settle a deformity. New four improvements are proposed.

\section{PROPOSED WORK}

\section{A. Artificial Neural Network}

Fake Neural system is characterized as a framework where information can be prepared through various hubs like neurons in cerebrum. Every hub is assigned with a capacity and it determines the hub yield with the help of some standard ammeters accessible locally to it for an arrangement of given information. By modifying weight of these parameters the hub capacity can be modified as planned

\section{B. Neural Network Modeling}

Like a brain, a neural system likewise plays out a comparable design. It makes them learn mechanism planned inside it form modeling the reliability.[31-35] A number of nervous constitute Neural Network which is basic processing components. These neurons are connected to each other straightforwardly through communications links

associated with some weight. Supervised learning method is utilize $d$ to prepare the Neural Network with a progression of test input and to comp are the asset general $f$ or the pre indicated period of time with the normal example output. The preparation strategy is completed until expected and persuading reactions are given by the network. The neurons are organized layer by layer and the association pattern $s$ inside and in the middle of layers make the system design. He network can be either single-layered or multi-layered; layers of interconnected connects between the neuron sections hinder mine it.

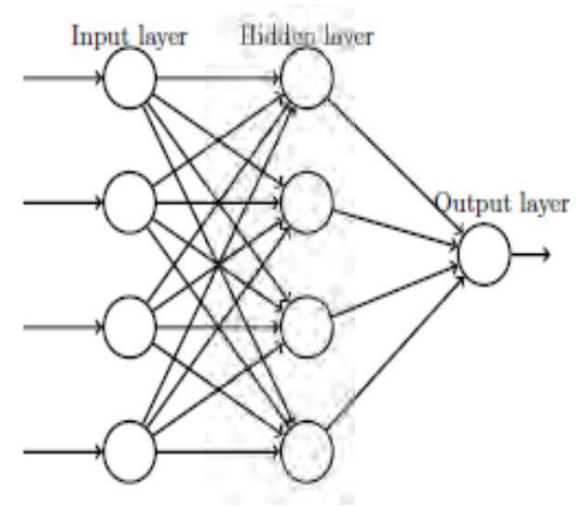

\section{PREDICTING MODELS}

In the previous couple of years, many predicting models were acquainted with estimate the adaptation to non-critical failure of programming. The 
issue of building growth models was the subject of numerous exploration work $\mathrm{s}$ which helps in estimating the adaptation to internal failure limit of a product framework before it is handover to the customer or discharged. This paper principallycenterson [36-40]the adaptation to non-critical failure of the product utilizing manufactured neural system utilizing back propagation calculation.

\section{EXPLORAORY RESULT}

We are utilizing python as a programming dialect. Jumpy and neuromas structure is utilized for usage of the neural systems. The system comprises of Input neurones, concealed layer and yield neurones. Each neurone has some weight. This weight is alteringduring the preparation stage. $[41,42]$ We prepare the system utilizing dataset. The system is prepared for 500 ages. Sigmoid is utilized as initiation work for the system.

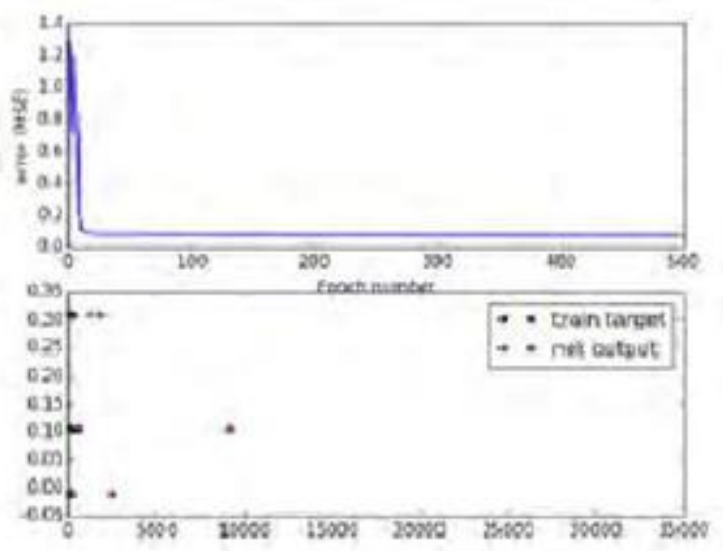

The beneath figure indicates blunder ascertained at a few ages

On the off chance that there is some blunder at that point weights of the every hub is balanced in order to limit this mistake. From this chart we can state that after some age blunder end up steady. So we can stop the preparation of the information. After the preparation is done we at that point test the system.

\section{CONCLUSION}

This paper accentuation on the product blame forecast system which depends on manufactured neural system with back engendering learning calculation. The perception and results presume that the neural system show performs better as far as less mistake in expectation when contrasted with existing investigative models and consequently it is smarter to do programming flaw forecast tests utilizing neural systems. Be that as it may it can be seen that the neural Network technique proposed in this paper utilizing back spread calculation give a solid match. As the association weights are haphazardly introduced, in this way the neural system gives diverse outcomes for dataset and subsequently the execution of system changes. The value of neural system is strategy is reliant on the idea of dataset up to more prominent degree.

\section{REFERENCES}

[1] Kumaravel A., Rangarajan K.,Algorithm for automaton specification for exploring dynamic labyrinths, Indian Journal of Science and Technology,V-6,I-SUPPL5,PP-4554-4559,Y-2013

[2] P. Kavitha, S. Prabakaran "A Novel Hybrid Segmentation Method with Particle Swarm Optimization and Fuzzy C-Mean Based On Partitioning the Image for Detecting Lung Cancer" International Journal of Engineering and Advanced Technology (IJEAT) ISSN: 2249-8958, Volume-8 Issue-5, June 2019

[3] Kumaravel A., Meetei O.N.,An application of non-uniform cellular automata for efficient cryptography,2013 IEEE Conference on Information and Communication Technologies, ICT 2013,V-,I-,PP-1200-1205,Y-2013

[4] Kumarave A., Rangarajan K.,Routing alogrithm over semi-regular tessellations,2013 IEEE Conference on Information and Communication Technologies, ICT 2013,V-,I-,PP-1180-1184,Y-2013

[5] P. Kavitha, S. Prabakaran "Designing a Feature Vector for Statistical Texture Analysis of Brain Tumor" International Journal of Engineering and Advanced Technology (IJEAT) ISSN: 2249-8958, Volume-8 Issue-5, June 2019

[6] Dutta P., Kumaravel A.,A novel approach to trust based identification of leaders in social networks,Indian Journal of Science and Technology,V-9,I-10,PP--,Y-2016

[7] Kumaravel A., Dutta P.,Application of Pca for context selection for collaborative filtering,Middle - East Journal of Scientific Research,V-20,I-1,PP-88-93,Y-2014

[8] Kumaravel A., Rangarajan K.,Constructing an automaton for exploring dynamic labyrinths,2012 International Conference on Radar, Communication and Computing, ICRCC 2012,V-,I-,PP-161-165,Y-2012

[9] P. Kavitha, S. Prabakaran "Adaptive Bilateral Filter for Multi-Resolution in Brain Tumor Recognition" International Journal of Innovative Technology and Exploring Engineering (IJITEE) ISSN: 2278-3075, Volume-8 Issue-8 June, 2019

[10] Kumaravel A.,Comparison of two multi-classification approaches for detecting network attacks, World Applied Sciences Journal,V-27,I-11,PP-1461-1465,Y-2013

[11] Tariq J., Kumaravel A.,Construction of cellular automata over hexagonal and triangular tessellations for path planning of multi-robots,2016 IEEE International Conference on Computational Intelligence and Computing Research, ICCIC 2016,V-,I-,PP--,Y-2017

[12] Sudha M., Kumaravel A.,Analysis and measurement of wave guides using poisson method,Indonesian Journal of Electrical Engineering and Computer Science,V-8,I-2,PP-546-548,Y-2017

[13] Ayyappan G., Nalini C., Kumaravel A., Various approaches of knowledge transfer in academic social network,International Journal of Engineering and Technology,V-,I-,PP-2791-2794,Y-2017

[14] Kaliyamurthie, K.P., Sivaraman, K., Ramesh, S. Imposing patient data privacy in wireless medical sensor networks through homomorphic cryptosystems 2016, Journal of Chemical and Pharmaceutical Sciences 92.

[15] Kaliyamurthie, K.P., Balasubramanian, P.C. An approach to multi secure to historical malformed documents using integer ripple transfiguration 2016 Journal of Chemical and Pharmaceutical Sciences 92.

[16] A.Sangeetha,C.Nalini,"Semantic Ranking based on keywords extractions in the web", International Journal of Engineering \& Technology, 7 (2.6) (2018) 290-292

[17] S.V.GayathiriDevi,C.Nalini,N.Kumar,"An efficient software verification using multi-layered software verification tool "International Journal of Engineering \& Technology, 7(2.21)2018 454-457

[18] C.Nalini,ShwtambariKharabe,"A Comparative Study On Different Techniques Used For Finger - Vein Authentication”, International Journal Of Pure And Applied Mathematics, Volume 116 No. 8 2017, 327-333, Issn: 1314-3395

[19] M.S. Vivekanandan and Dr. C. Rajabhushanam, "Enabling Privacy Protection and Content Assurance in Geo-Social Networks", International Journal of Innovative Research in Management, Engineering and Technology, Vol 3, Issue 4, pp. 49-55, April 2018.

[20] Dr. C. Rajabhushanam, V. Karthik, and G. Vivek, "Elasticity in Cloud

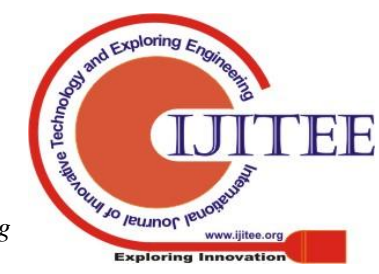




\section{Software Error Indication using Artificial Neural Network and Strong Back Propagation}

Computing", International Journal of Innovative Research in Management, Engineering and Technology, Vol 3, Issue 4, pp. 104-111, April 2018.

[21] K. Rangaswamy and Dr. C. Rajabhushanamc, "CCN-Based Congestion Control Mechanism In Dynamic Networks", International Journal of Innovative Research in Management, Engineering and Technology, Vol 3, Issue 4, pp. 117-119, April 2018.

[22] Kavitha, R., Nedunchelian, R., "Domain-specific Search engine optimization using healthcare ontology and a neural network backpropagation approach", 2017, Research Journal of Biotechnology, Special Issue 2:157-166

[23] Kavitha, G., Kavitha, R., "An analysis to improve throughput of high-power hubs in mobile ad hoc network", 2016, Journal of Chemical and Pharmaceutical Sciences, Vol-9, Issue-2: 361-363

[24] Kavitha, G., Kavitha, R., "Dipping interference to supplement throughput in MANET" , 2016, Journal of Chemical and Pharmaceutical Sciences, Vol-9, Issue-2: 357-360

[25] Michael, G., Chandrasekar, A.,’Leader election based malicious detection and response system in MANET using mechanism design approach", Journal of Chemical and Pharmaceutical Sciences(JCPS) Volume 9 Issue 2, April - June 2016

[26] Michael, G., Chandrasekar, A.,"Modeling of detection of camouflaging worm using epidemic dynamic model and power spectral density", Journal of Chemical and Pharmaceutical Sciences(JCPS) Volume 9 Issue 2, April - June 2016.

[27] Pothumani, S., Sriram, M., Sridhar, J., Arul Selvan, G., Secure mobile agents communication on intranet,Journal of Chemical and Pharmaceutical Sciences, volume 9, Issue 3, Pg No S32-S35, 2016

[28] Pothumani, S., Sriram, M., Sridhar, Various schemes for database encryption-a survey, Journal of Chemical and Pharmaceutical Sciences, volume 9, Issue 3, Pg NoS103-S106, 2016

[29] Pothumani, S., Sriram, M., Sridhar, A novel economic framework for cloud and grid computing, Journal of Chemical and Pharmaceutical Sciences, volume 9, Issue 3, Pg No S29-S31, 2016

[30] Priya, N., Sridhar, J., Sriram, M. "Ecommerce Transaction Security Challenges and Prevention Methods- New Approach" 2016 ,Journal of Chemical and Pharmaceutical Sciences, JCPS Volume 9 Issue 3.page no:S66-S68 .

[31] Priya, N.,Sridhar,J.,Sriram, M."Vehicular cloud computing security issues and solutions" Journal of Chemical and Pharmaceutical Sciences(JCPS) Volume 9 Issue 2, April - June 2016

[32]

[33] Priya, N., Sridhar, J., Sriram, M. "Mobile large data storage security in cloud computing environment-a new approach" JCPS Volume 9 Issue 2. April - June 2016

[34] Anuradha.C, Khanna.V, "Improving network performance and security in WSN using decentralized hypothesis testing "Journal of Chemical and Pharmaceutical Sciences(JCPS) Volume 9 Issue 2, April - June 2016

[35] Anuradha.C, Khanna.V, "A novel gsm based control for e-devices" Journal of Chemical and Pharmaceutical Sciences(JCPS) Volume 9 Issue 2, April - June 2016

[36] Anuradha.C, Khanna.V, "Secured privacy preserving sharing and data integration in mobile web environments " Journal of Chemical and Pharmaceutical Sciences(JCPS) Volume 9 Issue 2, April - June 2016 .

[37] Sundarraj, B., Kaliyamurthie, K.P. Social network analysis for decisive the ultimate classification from the ensemble to boost accuracy rates 2016 International Journal of Pharmacy and Technology 8

[38] Sundarraj, B., Kaliyamurthie, K.P. A content-based spam filtering approach victimisation artificial neural networks 2016 International Journal of Pharmacy and Technology 83 .

[39] Sundarraj, B., Kaliyamurthie, K.P. Remote sensing imaging for satellite image segmentation 2016 International Journal of Pharmacy and Technology $8 \quad 3$.

[40] Sivaraman, K., Senthil, M. Intuitive driver proxy control using artificial intelligence 2016 International Journal of Pharmacy and Technology $8 \quad 4$

[41] Sivaraman, K., Kaliyamurthie, K.P. Cloud computing in mobile technology 2016 Journal of Chemical and Pharmaceutical Sciences 92.

[42] Sivaraman, K., Khanna, V. Implementation of an extension for browser to detect vulnerable elements on web pages and avoid click jacking 2016 Journal of Chemical and Pharmaceutical Sciences
92.

\section{AUTHORS PROFILE}

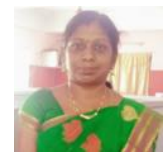

N.Priya Assistant Professor, Department of Computer Science \& Engineering, Bharath Institute of Higher Education and Research, Chennai, India

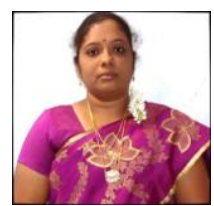

P.Nandhini, Assistant Professor, Department of Computer Science \& Engineering, Bharath Institute of Higher Education and Research, Chennai, India

D.Jeyapriya, Assistant Professor, Department of Computer Science \& Engineering, Bharath Institute of Higher Education and Research, Chennai, India

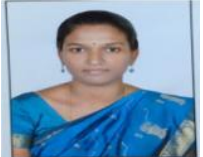

Nikita Sharma, Student, Department of Compute Science \& Engineering, Bharath Institute of Higher Education and Research, Chennai, India 